\title{
Analysis of Characteristics Pigment And Paper Excavated At The Site of Hoeamsa Temple (12th- Century), Korea
}

InHee Go

USTB: University of Science and Technology Beijing https://orcid.org/0000-0003-2511-1164

\section{Seong Woo Mun}

National Research Institute of cultural heritage

Jang Jon Lee

High heritage care

Hye Young Jeong ( $\nabla$ k75v45@gmail.com )

National Research Institute of Cultural Heritage

Research article

Keywords: Pigment, Hoeamsa Temple site, Paper, Bast fiber, Dancheong, Joseon Dynasty

Posted Date: August 24th, 2021

DOI: https://doi.org/10.21203/rs.3.rs-744858/v1

License: (c) (i) This work is licensed under a Creative Commons Attribution 4.0 International License.

Read Full License 


\section{Abstract}

One paper fragment and three pigments were excavated from earthenware found in the Hoeamsa Temple site (Historic Site No. 128), which is presumed to have been constructed in the 12th century. This study identifies the types and characteristics of the paper and pigments through methods such as fiber identification, pigment component analysis, and crystal structure analysis. Using the Graff ' $C$ ' staining method, the paper fragment is identified as paper-mulberry bast fiber (B. kazinoki Siebold), and according to radiocarbon dating results, the paper is believed to be from the Joseon Dynasty, between 1460 and 1640 , which is when the Hoeamsa temple was believed to have been rebuilt. The green pigment consists of cerussite, malachite, and ataccamite, while quartz, muscovite, and illite were detected in the white pigment, and quartz, hematite, illite, and kaolinite were detected in the red pigment. The $L^{*}$ value ranged from 41.59 to 79.05 . The white pigment showed the highest brightness value at 79.05 , while the green pigment was measured at 58.20 and the red pigment at 41.59 . The $a^{*}$ value ranged from -2.25 to 22.75 : the $a *$ value of the red pigment was the highest at 22.75 , the green pigment was the lowest at -2.25 . The $b^{*}$ value ranged from 7.44 to 26.26 : the $b^{*}$ value of the red pigment was the highest at 26.26 and the white pigment was the lowest at 7.44 .

These scientific data identified the raw materials of paper used during the Joseon Dynasty. In addition, the data can be used for repair and restoration of ancient dancheong (traditional Korean decorative coloring on wooden buildings and artifacts) by analyzing the composition of pigments and identifying the characteristics of crystal structure.

\section{Introduction}

The Yangju Hoeamsa Temple site, in Gyeonggi-do province, South Korea, was designated as Historic Site No. 128 in 1964 (Fig. 1a). Though its establishment date is not clear, the first documentary record of Hoeamsa Temple began with the book Dongguk Yeoji Seungram in 1174. It is detailed in the book Dongguk Yeoji Seungram (1481) that envoys from the Jin dynasty visited Hoeamsa Temple. And the monument to Taegosa Wonjeung Guksa in Goyang, Korea is Treasure No. 611. This monument was erected to commemorate Wonjeungguksa (1301-1382), a monk in the late Goryeo Dynasty. According to the record, "I left home at the age of 13 and became a disciple of Gwangji at Hoeamsa," it is confirmed that Hoeamsa was already built in at least 1313. Despite being located in a mountainous region, a south corridor was built that could be seen from temples in the plains and that exhibited the palace and temple arrangement styles of the Goryeo Dynasty [1-3]. The record of Hoeamsa Temple continues until 1976; therefore, it is estimated to have been constructed in the 12th century.

According to Lee [4], analytical research of pigments in Korea began after John Winter's study on the component analysis of ancient Korean pigments [5]. Throughout the 1990s and 2000s [6], researchers actively conducted analytical research of pigments applied to murals, portraits, and decorative paintings, and research on the reproduction and restoration of traditional pigments have found whiting, noerok, hematite, copper pigments, and ink to be the main ingredients[7, 8]. Innovation in this field continues and 
recent efforts have been made to solve existing analytical techniques limitations or to apply new ones. Analytical studies are increasing every year on various cultural property pigments, including murals, Buddhist paintings, portraits, decorative paintings, and dancheong $[4,9]$.

In Korea, due to the rapid progress of industrialization since the 1970s, dancheong pigments have are being replaced by chemical pigments, which are cheap and have good color fastness. In 2014, regarding dancheong construction in the standard specification for cultural property repair [10], it is stipulated that certain materials are used for the dancheong pigments and color numbers were designated in the specification, whilst chemical pigments are reported as a type of dancheong pigment. In addition, dancheong pigments are used based on the contents of the standard specification, unless otherwise specified in the design or instructed by the responsible authority. Consequently, the use of traditional dancheong pigments is decreasing, and the remaining ancient dancheong architecture is being reformed with chemical pigments.

It is mentioned in Lee's research that the main focus of the research related to pigment analysis, reproduction, and restoration of colored cultural properties are the pigment mixed in murals, Buddhist paintings, general paintings (portraits and decorative paintings), dancheong record paintings, and lacquerware. Among these, the majority of analytical research is on mural pigments, followed by general paintings such as portraits and decorations. However, there are relatively few analytical studies on Buddhist paintings and dancheong record paintings in the existing literature. There is additionally insufficient data and records on both the use of mineral pigments obtained from nature, and the current state of the remaining ancient dancheong buildings, which are declining in number due to reformation with chemical pigments. Consequently, it is difficult to secure scientific data concerning ancient dancheong.

Research Aim: The aim of this study is to investigate and examine the found ancient paper and pigments. This research is expected to identify the pigments used in early and mid-Joseon Dynasty (1392-1776) and to reproduce the colors of traditional dancheong pigments. The raw materials of the paper fragment were identified through the morphological characteristics of the fibers, and the dates were estimated by radiocarbon dating. The characteristics of the pigments were confirmed through analysis of component, particle size, color, and crystal structure. These characteristics allow an estimation of the way ancient people made the pigment so that the pigments can be reproduced in the same way.

\section{Materials And Analysis Methods}

\subsection{Materials}

The samples used in this study were pigments excavated from the Yangju Hoeamsa Temple Site (Fig. $1 \mathrm{~b})$ : the pigments were wrapped in paper and placed in pottery. There were 16 pigments and 1 paper fragment. Based on color, three samples were selected from the 16 pigments, which were relatively 
unmixed. Figure 2 demonstrates the excavated pottery (Fig. 2a), pigments (Fig. 2b, c, d), and paper (Fig. 2e).

\subsection{Analysis Methods 2.2.1. Paper Analysis}

The paper fiber identification was based on the Graff ' $C$ ' method, which is accessible in ISO 9184-4, and the fiber morphology was observed using a Nikon fluorescent microscope (ECLIPSE Ni, Japan) [11]. A low vacuum electron microscope (Hitachi TM3000, Japan) was used to observe the sample surface.

The excavated pigments and paper specimens were radiocarbon dated using the accelerator mass spectrometer (AMS) 1MV HVE 4110 (HVEE, Netherlands). For sample pretreatment, the paper specimen was washed with deionized water to remove soil on the surface and chemically treated using the AAA method $(0.5 \mathrm{M} \mathrm{HCl}, 0.1 \mathrm{NaOH}, 0.5 \mathrm{M} \mathrm{HCl})$. The program Oxcal v4.2.4 was used to convert the radiocarbon dating into calendar dating, and the Intcal13 calibration curve was applied [12].

\subsubsection{Pigment Analysis}

The stereomicroscope BX51 from Olympus was used to confirm whether the pigments excavated from the Hoeamsa Temple site were mixed. In order to measure the color difference of the pigments, a color difference meter (spectro-guide) from Gardner was used to express $C I E L^{*}, a^{*}$, and $b^{*}$ values. X-ray diffraction spectroscopy (MEPYREAN, Panalyical, Netherlands) was used to analyze the main component minerals of the pigments. The analysis conditions were $40 \mathrm{kV}, 40 \mathrm{~mA}, 2$ theta, range of $5-80^{\circ}$, scanning interval of $0.04^{\circ}$, and scanning time of 0.5 seconds, and measurements were performed through the continuous scan method. To analyze the microstructure of the excavated pigments, Scanning electron microscopy-energy dispersive spectroscopy (SEM-EDS) was applied through SEM of Jeol (JSM-5910LV, Japan), and the surface of the pigments were coated in platinum (Pt). The principal element analysis was conducted using an x-ray fluorescence spectrometer (Zetium, Panalyical, Netherlands). The white pigments and red pigments were analyzed using a standard calibration curve, while the green pigments were analyzed using the software Omnian, a semi-quantitative program using standard samples provided by Panalytical. To measure the particle-size distribution, $0.2 \mathrm{~g}$ of the pigment was dispersed for 24 hours using $20 \mathrm{ml}$ of $1 \%$ sodium hexametaphosphate (Sigma-Aldrich), and Masterisizer 2000 (Malvern, England) was used.

\section{Results And Discussion}

\subsection{Paper Analysis}

\subsubsection{Morphological Characteristics}

An excavated paper fragment with pigments is shown in the photographs below (Fig. 3). 
The fibers of the paper wrapping the pigments reacted by turning reddish brown in the Graff ' $C$ ' dye [13]. As shown in Image $\mathrm{C}$ of Fig. 4, the transparent membrane enveloped around the fiber and the crossmarking, dislocation, and longitudinal striations of the fiber were observed,thereby confirming that the specimen is paper-mulberry bast fiber $[14,15]$.

The surface of a paper fragment was magnified and examined with a scanning electron microscope. As with the optical microscope, this allowed the observation of the anatomical characteristics of the bast fibers (Fig. 5)

\subsubsection{Radiocarbon Dating}

As in Fig. 6, the radiocarbon dating of the paper sample was found to be $340 \pm 30$ (BP). Years BP (before present) was calculated in the 1950 s using the Libby half-life ( $5568 \pm 30$ years): the year 1950 was set as 0 , as there was a drastic change in the ratio of radiocarbon components in the atmosphere, and thus dating is difficult to measure after this time $[16,17]$

According to Fig. 6, Table 1, through radiocarbon dating, the paper sample was determined to be from AD 1460-1640 with $95 \%$ confidence interval and an error range of 180 years. According to Kim Hong-sik [18], "Hoeamsa has been a subject of interest to many people as a grand Buddhist temple of the last Goryeo Dynasty and early Joseon Dynasty period. "Hoeamsa was reconstruction took place after 1472..." Furthermore, "the appearance of the architecture is very similar to the late Goryeo Dynasty and early Joseon Dynasty."

The period of origin of the paper is therefore considered to be between the early and mid-Joseon Dynasty, and it is judged to have been manufactured after the establishment of Hoeamsa.

Table 1

Result of radiocarbon dating

\begin{tabular}{|lll|}
\hline Radiocarbon date & \multicolumn{2}{l|}{ Calibrated data ${ }^{14} \mathrm{C}$ date range } \\
\hline$(\mathrm{yrBP} \pm 1 \sigma)$ & $\pm 1 \sigma$ Date range $(68.2 \%)$ & $\pm 2 \sigma$ Date range $(95.4 \%)$ \\
\hline $340 \pm 30$ & $1490 \mathrm{AD}(23.2 \%) 1530 \mathrm{AD}$ & 1460AD (95.4\%) 1640AD \\
& $1550 \mathrm{AD}(45.0 \%) 1640 \mathrm{AD}$ & \\
\hline
\end{tabular}

\subsection{Pigment Analysis}

\subsubsection{Microscopy observation}

Close-up images were captured via stereomicroscope to more precisely observe the pigments excavated from the Hoeamsa temple site, and green, red, and white pigments were detected (Fig. 7). Green pigment was mixed with the red pigment (Fig. 7a), while white pigment was partially mixed with red pigment (Fig. 7b), and red pigment was partially mixed with the white pigment (Fig. 7c).

\subsubsection{Color Difference Analysis}


The $L^{*}$ value, which measures brightness, ranges from 41.59 to 79.05 . The white pigment showed the highest brightness value at 79.05, while the green pigment was 58.20 and the red pigment was 41.59 . The $a^{*}$ value, which indicates the measure of green $\left(-a^{*}\right)$ and red $\left(+a^{*}\right)$, ranged from -2.25 to 22.75 . The $a^{*}$ value of the red pigment was the highest at 22.75 , while the $a^{*}$ value of the green pigment was the lowest at -2.25 . The $b^{*}$ value, which indicates the measure of blue $\left(-b^{*}\right)$ and yellow $\left(+b^{*}\right)$, ranged from 7.44 to 26.26 . The $b^{\star}$ value of the red pigment was the highest at 26.26 , while $b^{\star}$ of the white pigment was the lowest at 7.44 (Fig. 8).

\subsubsection{Component Mineral Analysis}

An x-ray diffraction analysis was performed to identify the mineral species of the green, white, and red pigments (Fig. 9). Quartz was detected in all of the pigments. The green pigment showed peaks of malachite, atacamite, cerussite, and quartz, and a small amount of illite. The white pigment showed mostly quartz, muscovite, and illite, and the red pigment showed quartz, hematite, illite, and kaolinite.

\subsubsection{SEM-EDS Analysis}

Based on the SEM-EDS mapping analysis (Table 2), Cu comprised $4.09 \%$ of Green, and C, O, Si, $\mathrm{Pb}$, and $\mathrm{Cl}$ were also detected. This SEM-EDS result, which contains elements $\mathrm{Cu}$ and $\mathrm{Cl}$, supports the results of XRD. Previous studies have reported that atacamite particles are angled and very thick, and that lighter green particles have higher $\mathrm{Cu}$ and $\mathrm{Cl}$ content [21]. A small amount of atacamite is present with $\mathrm{Cl}$ content of $0.33 \%$. Therefore, the main component of green pigment is confirmed as malachite. The red pigment showed $7.81 \% \mathrm{Fe}$, and consists of $\mathrm{O}, \mathrm{C}, \mathrm{Si}$ and Al. The principal element of the white pigment is $\mathrm{Si}$ (18.46\%); O, C, Al, and $\mathrm{K}$ were also detected.

Table 2. Results of SEM-EDS mapping analysis

\begin{tabular}{|c|c|c|c|c|c|c|c|c|c|c|c|c|c|c|}
\hline Sample & & Gree & & & & & & ed & & & & White & & \\
\hline $\begin{array}{c}\text { Optical } \\
\text { microscope }\end{array}$ & & & & & & & & & & & & & & \\
\hline SEM-EDS & & & & & & Con & centra & ons & vt\%) & & & & & \\
\hline & $\mathrm{C}$ & $\mathrm{Mg}$ & $\mathrm{Al}$ & $\mathrm{Si}$ & $\mathrm{S}$ & $\mathrm{Cl}$ & $\mathrm{K}$ & $\mathrm{Ca}$ & $\mathrm{Ti}$ & $\mathrm{Cr}$ & $\mathrm{Fe}$ & $\mathrm{Cu}$ & $\mathrm{Sn}$ & Total \\
\hline Green & 64.9322 .36 & - & 0.78 & 4.77 & - & 0.33 & 0.41 & - & - & - & 0.191 .68 & 4.09 & 0.46 & 100 \\
\hline Red & 32.9743 .35 & 0.32 & 5.80 & 7.80 & - & - & 1.59 & - & 0.37 & - & 7.81 & - & - & 100 \\
\hline White & 16.0851 .22 & 0.77 & 7.42 & 18.46 & - & - & 4.12 & - & 0.58 & - & 1.35 & & & 100 \\
\hline
\end{tabular}


The microstructure results through SEM analysis are as blow (Table 3). It is reported that both malachite and chlorite are generally fibrous and have a variolitic and botryoidal structure with a spherical appearance when aggregation occurs [19]. As confirmed through SEM, fine spherical particles of the green pigment aggregated to form a single mass as a botryoidal structure. In previous studies, hematite was reported to be flat-like, and large with small aggregates layered together [20]. Hematite is known to appear as aggregates of fibrous crystals, or as mica hematite in a flat shape in sheets. In the red pigment the flat-like crystals, with smooth surfaces, were densely stacked and formed a single aggregate. Groups of fibrous crystals were also observed. It has been reported that quartz is so hard due to anhedral crystal growth and that in rare cases some crystals may exist in subhedral fragments of hexagonal prismatic form [19]. However, hexagonal or anhedral particles were not detected in the white pigment; the pigment showed a flat surface, thus differing from the form of the red pigment, and the white pigment had an amorphous shape. Only the surface of the particles is formed in a plate-shape, which was observed to be smooth.

Table 3. Microstructural observation of pigments and SEM-EDS point analysis results.

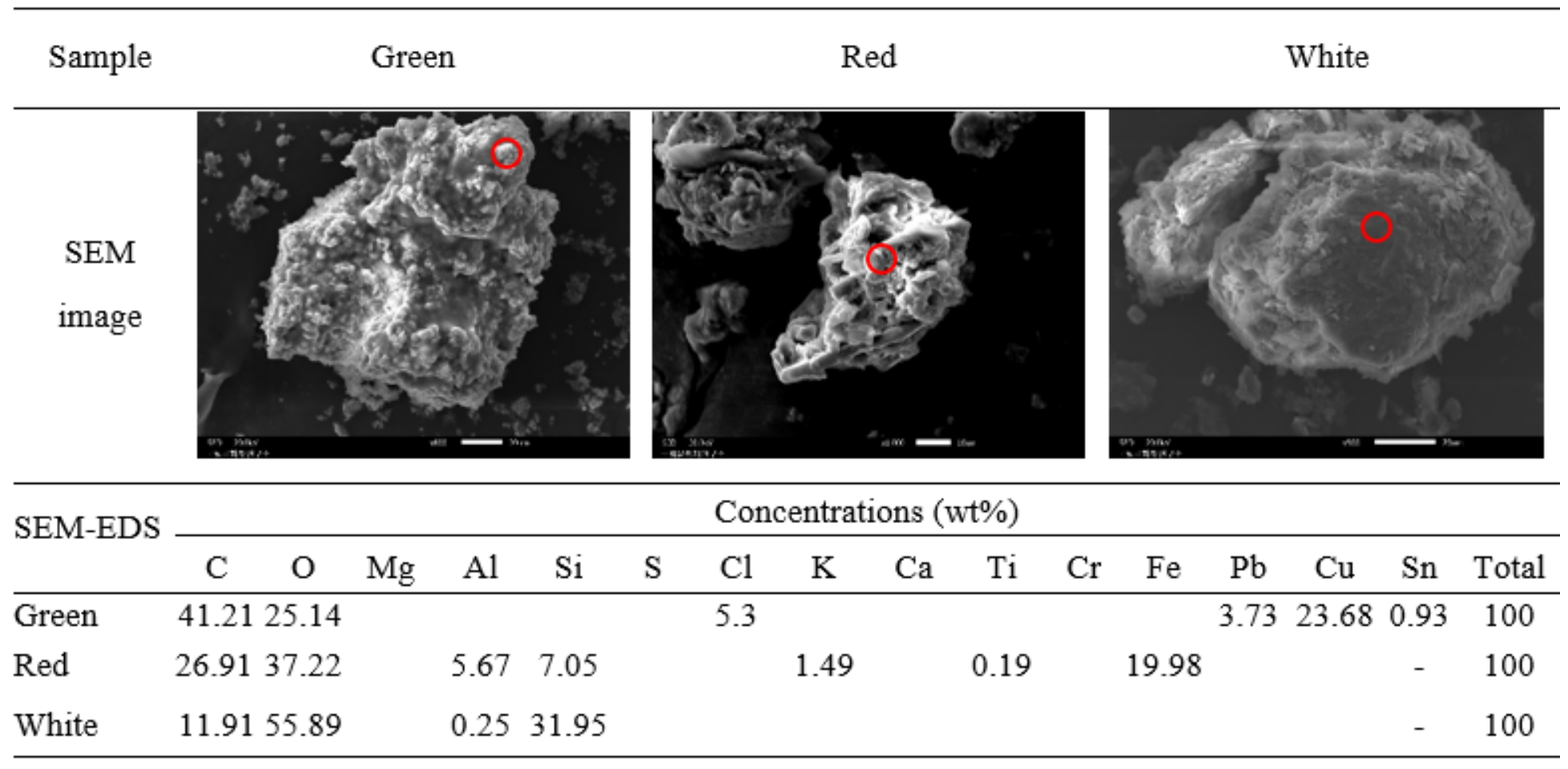

\subsubsection{Principal Element Analysis}

An x-ray fluorescence spectrometer was used to conduct a quantitative analysis of the principal elements of the pigments. The results of the green pigment are as follows: $\mathrm{SiO}_{2} 31.20 \mathrm{wt}$.\%, CuO 27.90wt.\%, $\mathrm{Al}_{2} \mathrm{O}_{3}$ 9.19wt.\%, and $\mathrm{PbO} 8.27 \mathrm{wt} . \%$. The results of the red pigment are as follows: $\mathrm{SiO}_{2} 40.60 \mathrm{wt} . \%, \mathrm{Fe}_{2} \mathrm{O}_{3}$ $24.90 \mathrm{wt} . \%$, and $\mathrm{Al}_{2} \mathrm{O}_{3} 19.80 \mathrm{wt} . \%$. The results of the white pigment are $\mathrm{SiO}_{2} 64.30 \mathrm{wt} . \%$ and $\mathrm{Al}_{2} \mathrm{O}_{3}$ 18.20wt.\% (Table 4). 
Table 4

Concentration of elements in green pigment

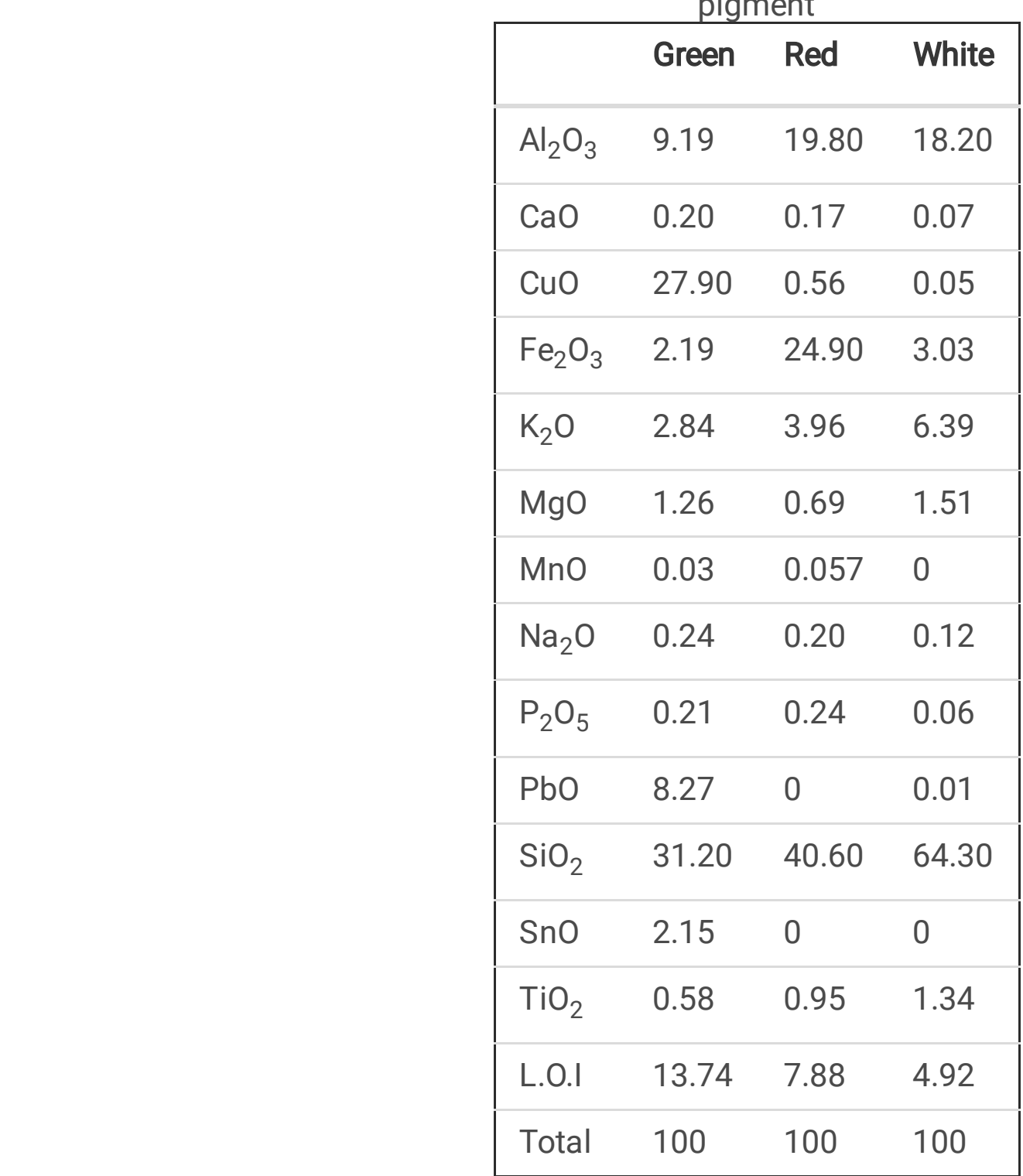

\subsubsection{Particle Size Analysis}

As in Fig. 10, the average particle size of the green pigment was the largest of the three pigments (52.44 $\mu \mathrm{m})$, followed by the red pigment $(35.88 \mu \mathrm{m})$ and the white pigment $(16.11 \mu \mathrm{m})$. As all three pigments have a distribution curve in the form of multiple peaks, it was judged that when preparing the pigments, they were neither purified to the same particle size nor separated according to particle size. The green pigment distribution ranges widely from $0.40 \otimes$ to $2000 \otimes$. In addition, the span value of 9.02 shows that it has the widest degree of sorting range of the three pigments. The span value was used to represent the distribution width of particles. The narrower the distribution, the smaller the value. The span value of the white pigment is 5.0 and that of the red pigment is 4.8 , the lowest degree of sorting.

\section{Conclusion}


This study investigated the morphological, radiocarbon dating, components, crystal structure, and particle sizes characteristics of three types of pigments and one type of paper fragment excavated from the Yangju Hoeamsa Temple site.

The paper sample excavated from Yangju Hoeamsa Temple site reacted as reddish-brown through Graff ' $C$ ' staining and showed the morphologic characteristics of a transparent membrane, cross-marking, and dislocation, thus indicating that it was made from paper-mulberry bast fiber. Through radiocarbon dating, it is estimated to have been made between AD 1460 to 1640 .

Based on a comprehensive consideration of the characteristics of the pigments, the green pigment contained a high amount of $\mathrm{Cu}$ and consisted of quartz, cerussite, malachite, and atacamite, thereby indicating that it is native copper. The main elements of the white pigment include $\mathrm{Si}$, $\mathrm{Al}$, and $\mathrm{K}$, with main component minerals of quartz, muscovite, and illite, indicating that it is white clay or pottery stone. The red pigment principally contained $\mathrm{Si}$ and $\mathrm{Fe}$, with component minerals of quartz, hematite, and a small amount of clay mineral. In particular, with $24 \%$ content of $\mathrm{Fe}_{2} \mathrm{O}_{3}$, it is considered to be an iron oxide pigment.

Based on the particle size analysis, the green pigment demonstrated a large average particle size of 52.44 , although the distribution range was wide. This result therefore portrayed the characteristic of a pigment production process without purification or particle size separation.

The major limitation of this study was the lack of materials. The recovered fragments are important artifacts, so samples were small and few. If enough samples were available, double staining would have allowed to estimate the ripening and purification of the raw fiber.

In this study, the pigments excavated from the Yangju Hoeamsa Temple site were packaged in paper and stored in earthenware. Identified the morphological characteristics of the paper sample, thus confirming that it is Hanji (traditional Korean paper) made from paper-mulberry fiber. Paper-mulberry bast fiber was used as a resource for fiber in the period between the early and mid-Joseon Dynasty. Based on the component analysis and crystal structure characteristics of the three types of pigments, this study not only identified the components of the pigments including native copper, quartz, muscovite, and hematite but also reflects the time period between the early and mid-Joseon Dynasty ()in which this type of paper and three types of pigments were used. The pigments' main purpose seems to have been for coloring, and it is hypothesized that the fragments found were remnants that were stored for later use. Accordingly, these results are expected to serve as basic data for the supply and usage of traditional pigments in Korea, and as scientific data to be used when needing to repair and to restore cultural assets utilizing traditional methods.

\section{Abbreviations}

AMS: accelerator mass spectrometer; SEM-EDS: Scanning electron microscopy-energy dispersive spectroscopy; arrow TM: Transparent membrane; arrow D: Dislocation; arrow C: Cross-marking; BP: 
before present; Cer: Cerussite; Qtz: Quartz; Mal: Malachite; Ata: Atacamite; Mus: Muscovite; Ilt: Illite; Hm: Hematite; Kao: Kaolinite;

\section{Declarations}

\section{Declaration of interest}

the authors specify that they have no conflicts of interest to declare.

\section{Availability of data and materials}

Not applicable

\section{Acknowledgements}

The authors would like to acknowledge Korea Institute of Geoscience and Mineral Resources, who provided assistances for the radiocarbon dating examinations. And Special thanks to the officials of the Gyeonggi Cultural Heritage Research Institute, Gyeonggi Cultural Foundation for supporting precious cultural heritage samples.

\section{Authors` contributions}

$\mathrm{IH}$ has designed and performed the experiments and entire data interpretation. $\mathrm{IH}$ and $\mathrm{HY}$ wrote the manuscript. SW and JJ performed the XRD, XRF. All authors read and approved the final manuscript.

\section{Competing interests}

The authors declares that they have no competing interests

\section{Funding}

This study was conducted as part of the National Research Institute of Cultural Heritage Cultural Heritage R\&D Project (Project number: NRICH-1605-C02F-1).

\section{References}

[1] S.Y. Lee, The Changes in the Construction Method of Full Floor Heating Ondol Facilites and its Meaning in the Early Joseon Dynasty: Revealed though the Ondol Remains of the Hoeam Temple Site, J. Korean Archaeological society. 2019;113(113):264-291.

[2] W.C. Cho, Architecture archeology review and characteristics of structures of Buddhist stupa's building in Hoeamsa temple, J. Local History and Culture. 2016;19(2):111-140.

[3] S.H. Kim, A study on development and utilization of content for Hoeamsa temple Site, J. Academic association of global cultural contents. 2018;35:43-61. 
[4] H.H. Lee, Research trend of the analysis and restoration study on traditional pigments, J. cultural heritage Studies. 2015;48(1):132-147.

[5] J, Winter; Composition analysis of ancient Korean pigments; J. Korean art and archaeology. 1989;43.

[6] B.H. berrie, Rethingking the history of artists' pigments through chemical analysis; Annual review of analytical chemistry. 2012;5:441-459.

[7] S.W. Mun, Y.S. Kang, J.S. Kim, G.H. Hwang, J.H. Park, S.M. Lee, H.Y. Jeong, Analysis on characteristics of pigments manufactured with various Neorok produced from Mt. Gwangjeongsan, Pohang; J. Conserv. Sci. 2020;36(6):533-540.

[8]J.S. Kim, H.Y. jeong, D.J. Byun, M.J. Yoo, M.N, Kim, S.M, Lee, Monitoring the change of physical properties of traditional Dancheong pigments; J. Conserv. Sci. 2020;36(6):549-561.

[9]L.L. Yao, Multi-analytical approach to the study of pigments and binding media in precious ancient polychrome cultural relics; Zhejiang University;2017. p.5-10.

[10] Standard specification for cultural property repair. https://www.cha.go.kr/cop/bbs/selectBoardList.do?bbsld=BBSMSTR_1045\&mn=NS_03_09_01 (2021). Accessed 17 May 2021.

[11] T.collings, D. Milner, The identification of oriental paper-making fibres; The paper conservator. 2010;3:51-79.

[12] B.C. Ramsey, Development of the radiocarbon calibration program; Radiocarbon. 2013;55(2):720730 .

[13] S. Adamopoulos, J.V. Oliver, Fiber composition of packaging grade papers as determined by the graff "C" staining test; J. wood and fiber science. 2006;38(4):567-575.

[14] M.S Ilvessalo-Pfäffli, Fiber atlas: identification of papermaking fibers, Springer, Berlin. 1995. p. 299.

[15] I.H. Isenberg, Pulp and paper microscopy, The institute of paper chemistry appleton, Wisconsin; 1967. p. 164-164.

[16] J.A. Yeon, W.K. Park, Wiggle matching radiocarbon dates of a buddhist wooden tablet (Bulpae) at Songkwangsa temple, Suncheon, Korea, J. Korea furniture society. 2014;25(1):55-60.

[16] H.S. Lee., H.J. Song, The study on the radiocarbon dating of Cheongok-dong archaeological site, Ulsan, conservation studies. 2006;27:181-201.

[18] H.S. Kim, A Study on Arrangement of a royal palace for Yangju archaeological Site, J. Munhwajae.1991;24:368. 
[19] N. Eastaugh, V. Walsh, T. Chaplin, R. Siddall, The pigment compendium-a dictionary of historical pigments, Butterworth-Heinemann, Burlington, Great Britain. 2004. p. 48, 54, 60, 330.

[20] Y.M. Yoo, M.S. Han, J.J. Lee, Species and characteristics of particles for traditional red and green pigments used in temples, J. Conserv. Sci.2014;30(4):365-372.

[21] M.S. Han, J.H. Kim, J.J. Lee, A scientific analysis of Dancheong pigments at Yaksajeon hall in Gwallyoungsa temple, J. cultural heritage studies.2014;47(1):18-31.

\section{Figures}
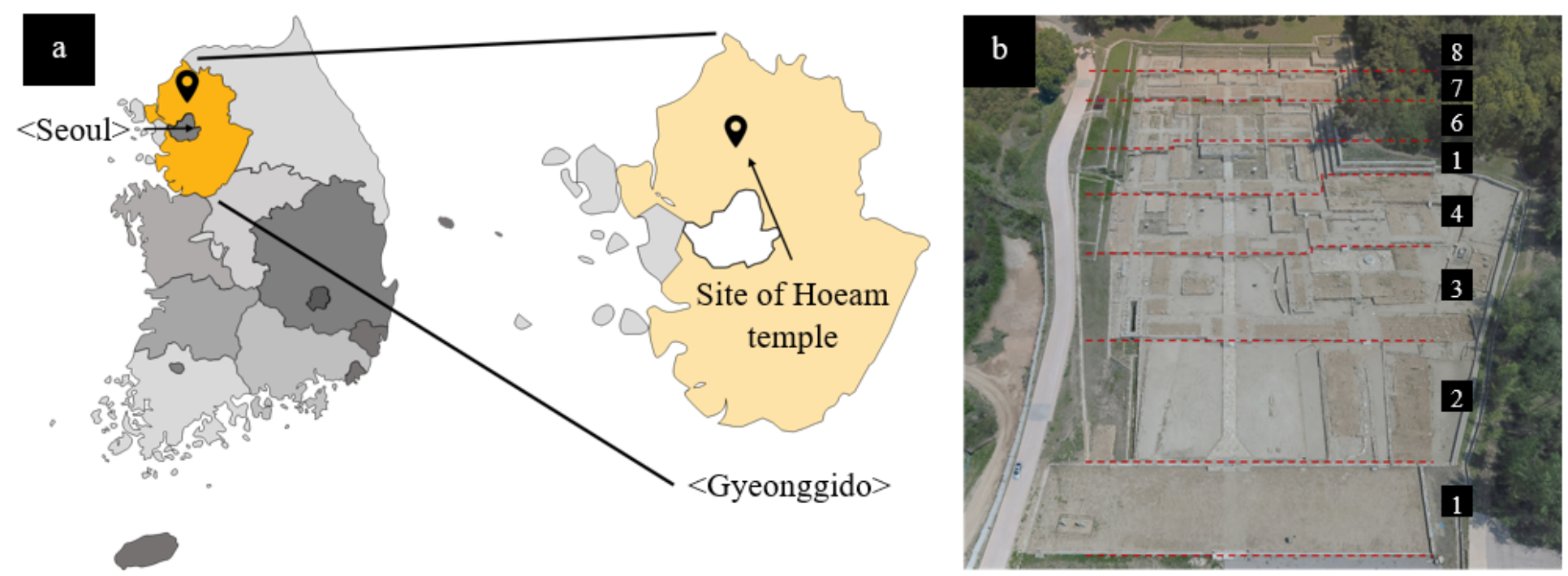

\section{Figure 1}

$a$ is the location of the archaeological sites of Hoeam temple, b consist of a total of 8 complexes by stonework
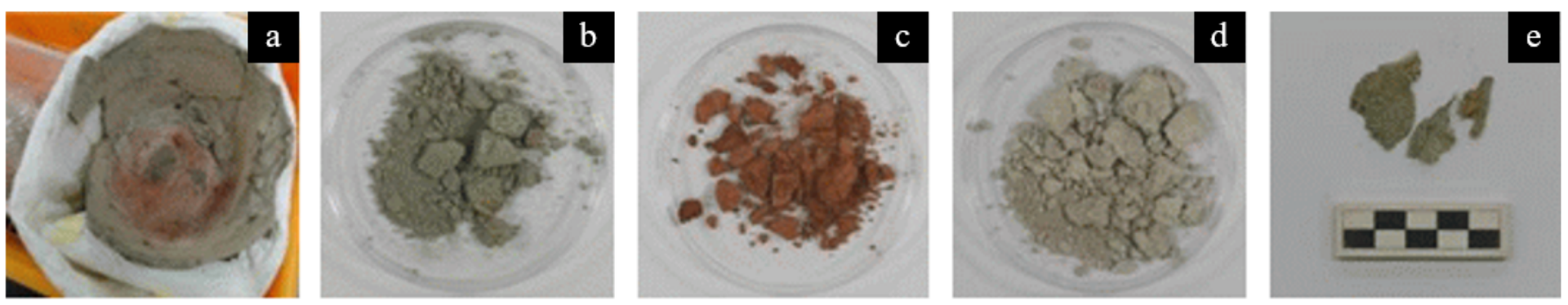

\section{Figure 2}

Pictures of relic (a: pottery containing pigments and paper, b: green pigment, b: red pigment, d: white pigment, e: paper) 

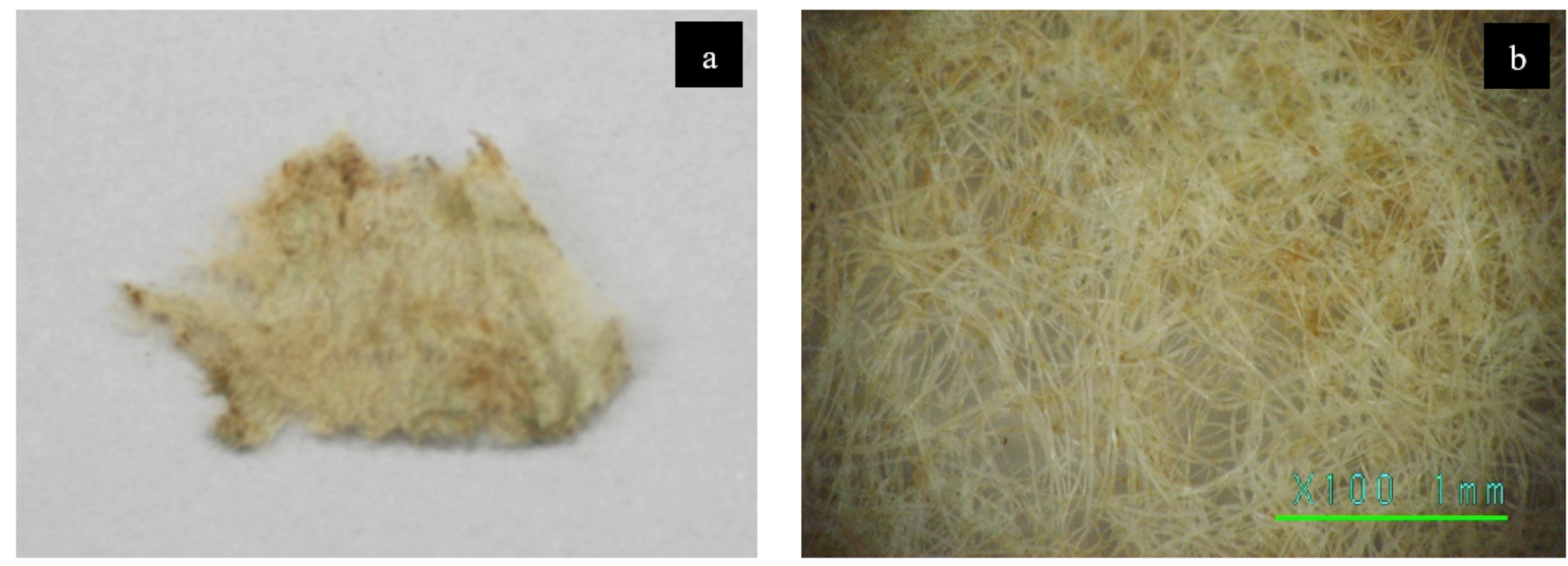

Figure 3

Photographs of the paper fragment (a: paper fragment, b: microscope image 100x)
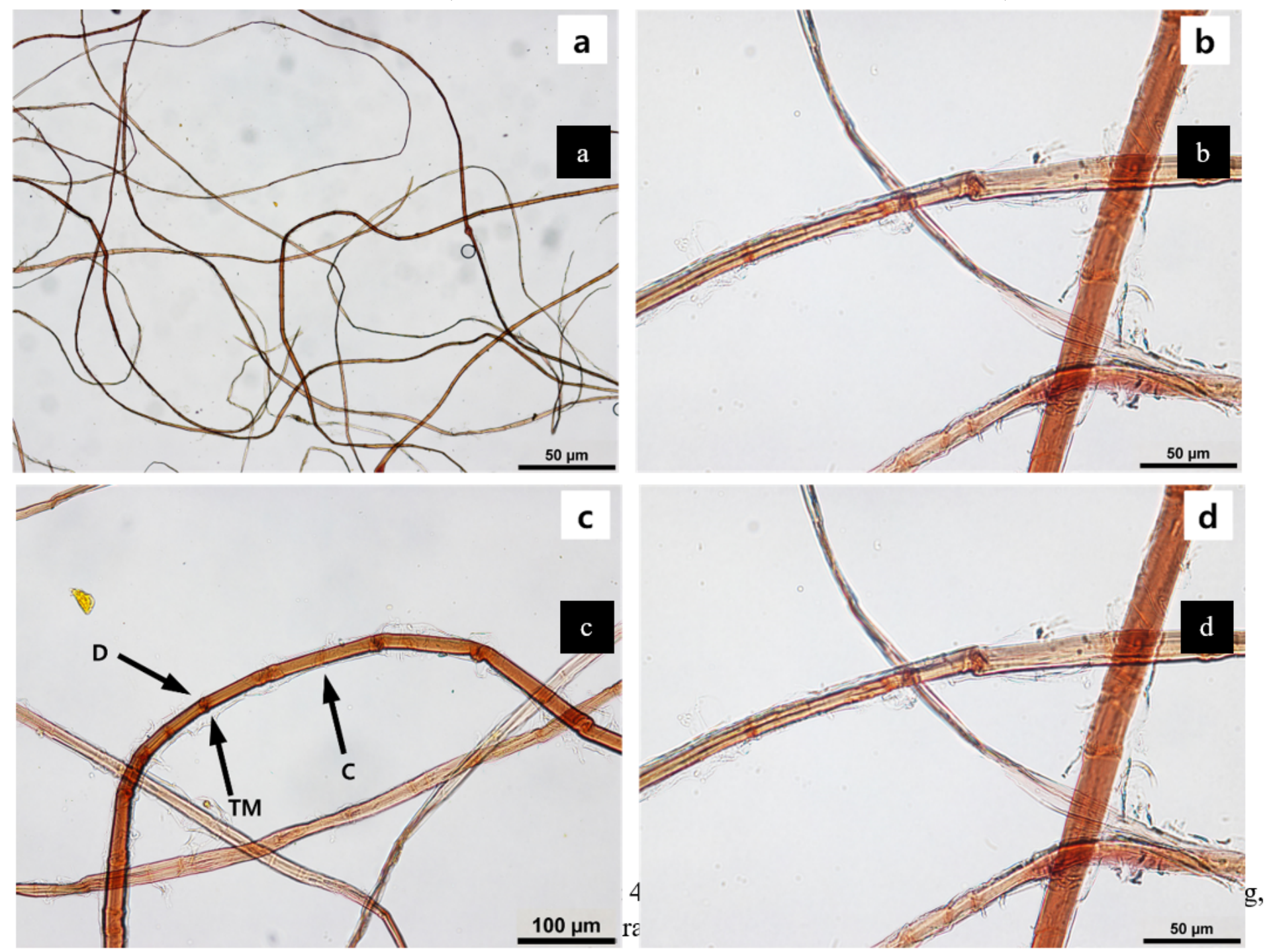

Figure 4 
Microscope Image of the fiber color reaction (a: 40x, b: 100x, b: 200x, d: 400x; Arrow C: Cross-marking, Arrow D: Dislocation, Arrow TM: Transparent membrane,)
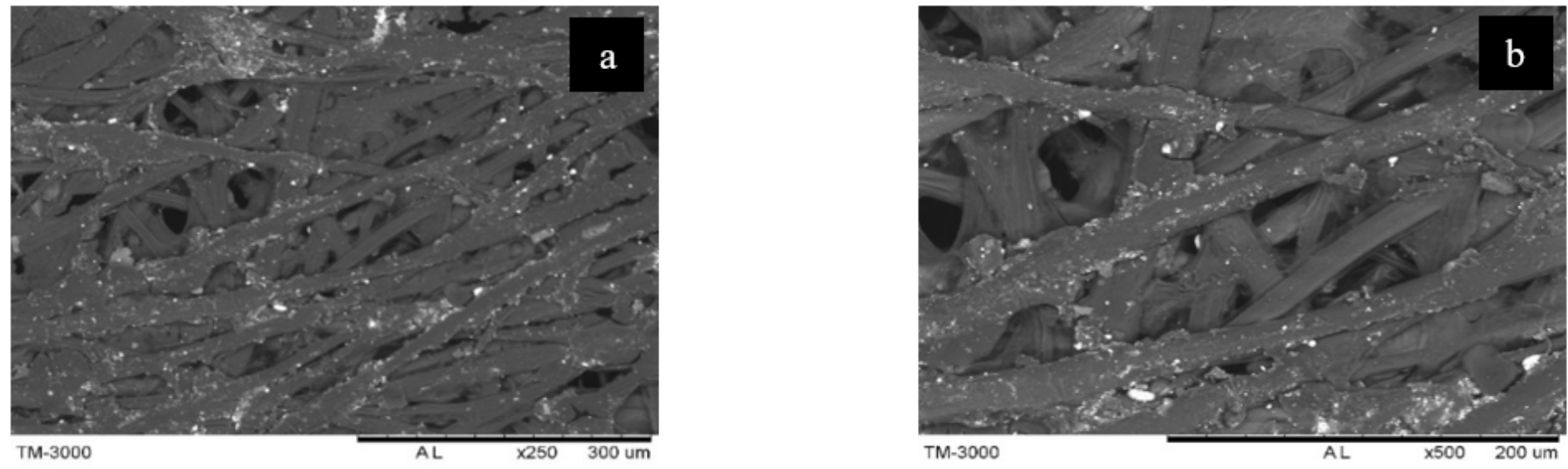

Figure 5

Surface image of the paper fragment (a: 250x, b: 500x)

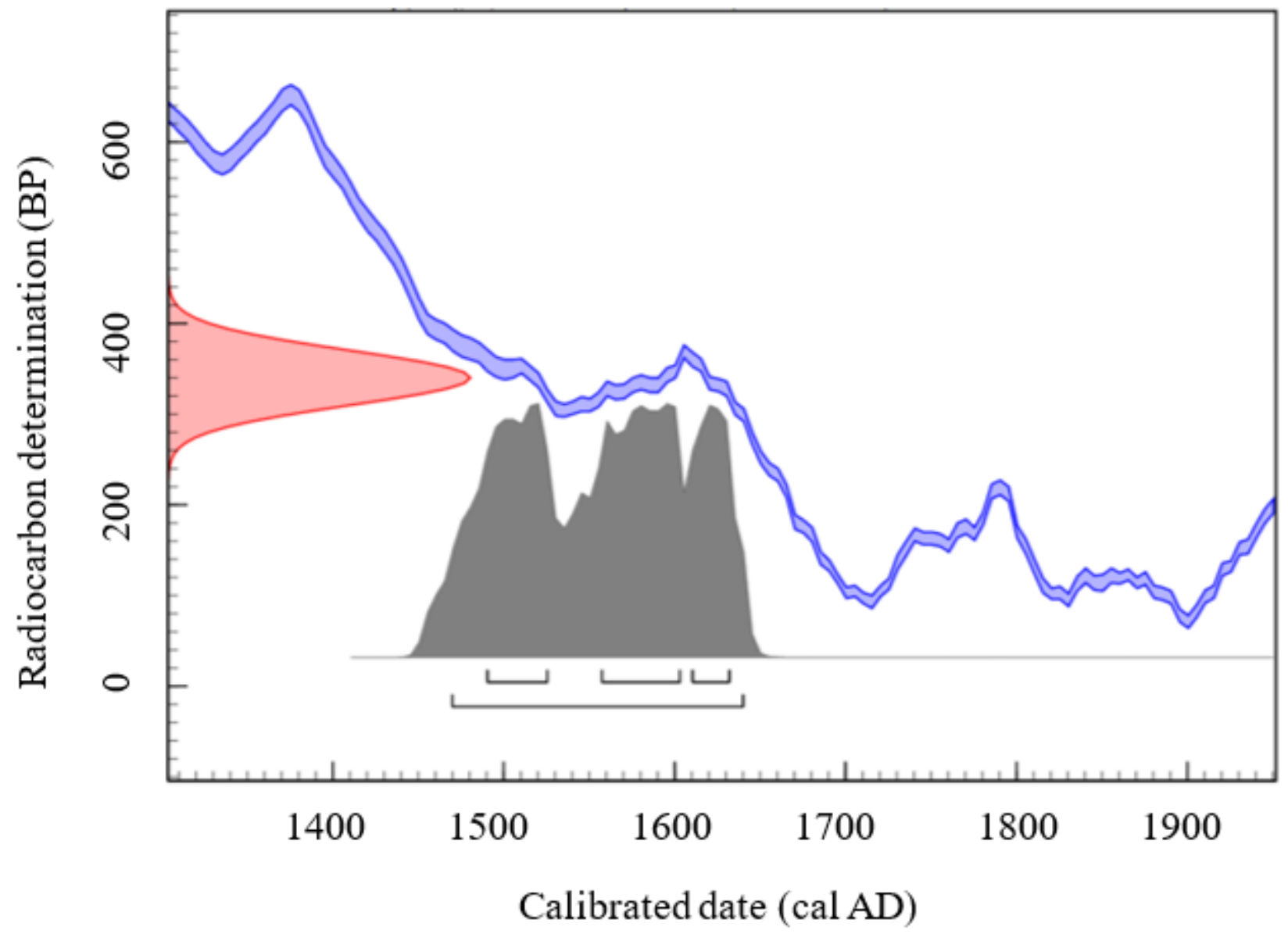

Figure 6

Probability profiles of radiocarbon date (Y-axis) and calibrated date (X-axis) for the paper fragment 

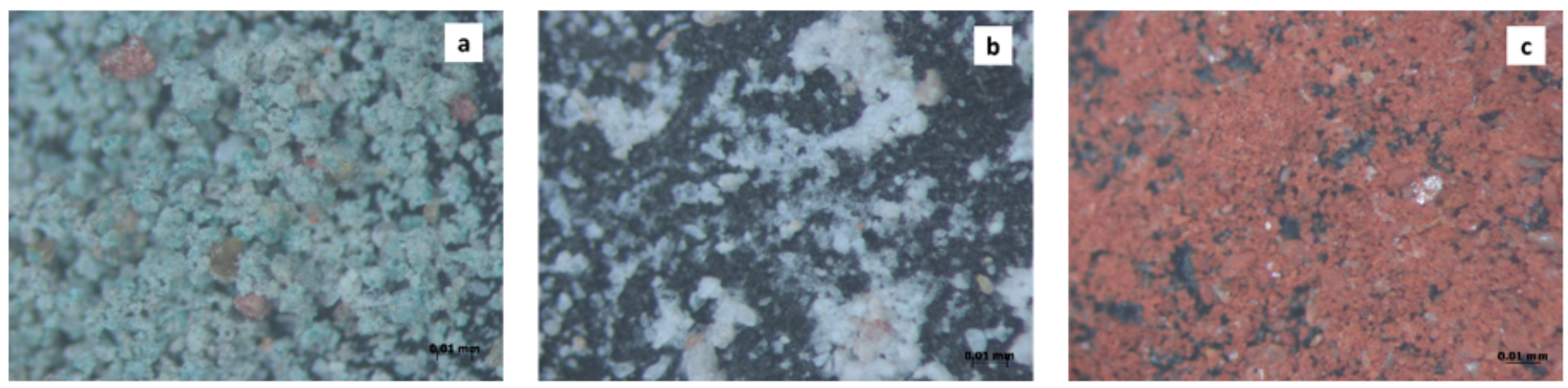

Figure 7

Image of optical microscopy (a: green pigment, b: white pigment, c: red pigment)

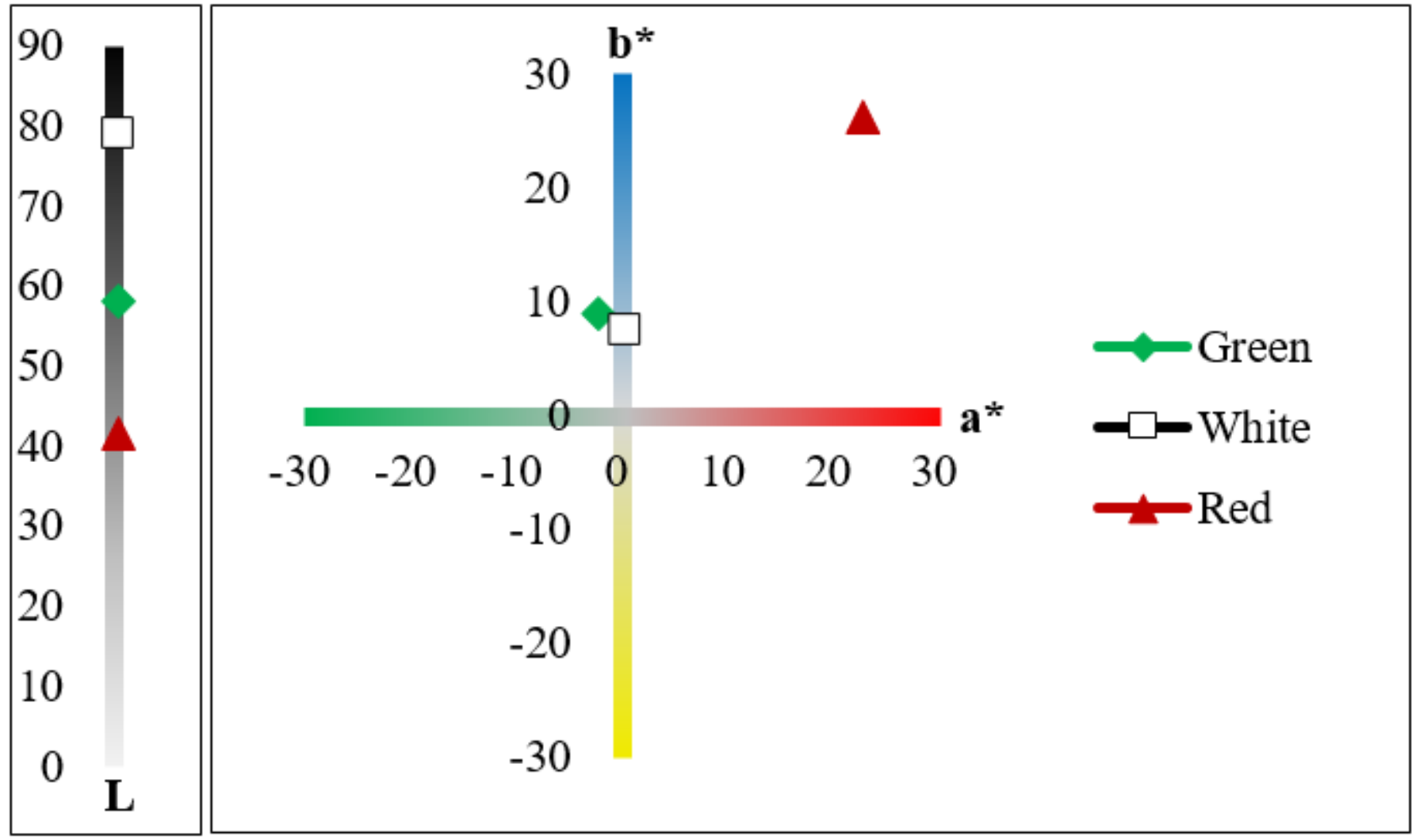

Figure 8

Chromaticity diagram of pigments 


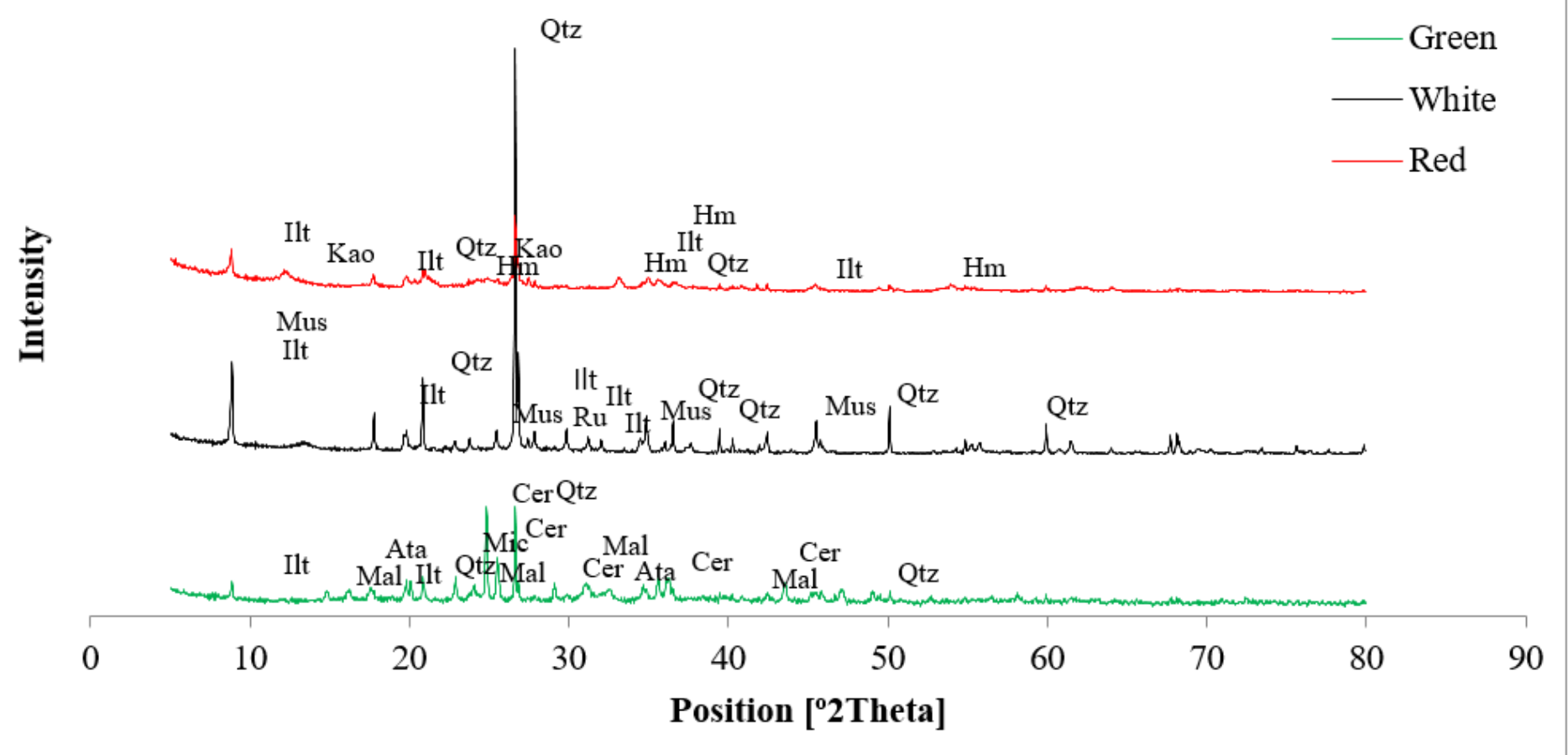

Figure 9

X-ray diffraction patterns for each pigment (Cer: Cerussite, Qtz: Quartz, Mal: Malachite, Ata: Atacamite, Mus: Muscovite, Ilt: Illite, Hm: Hematite, Kao: Kaolinite)

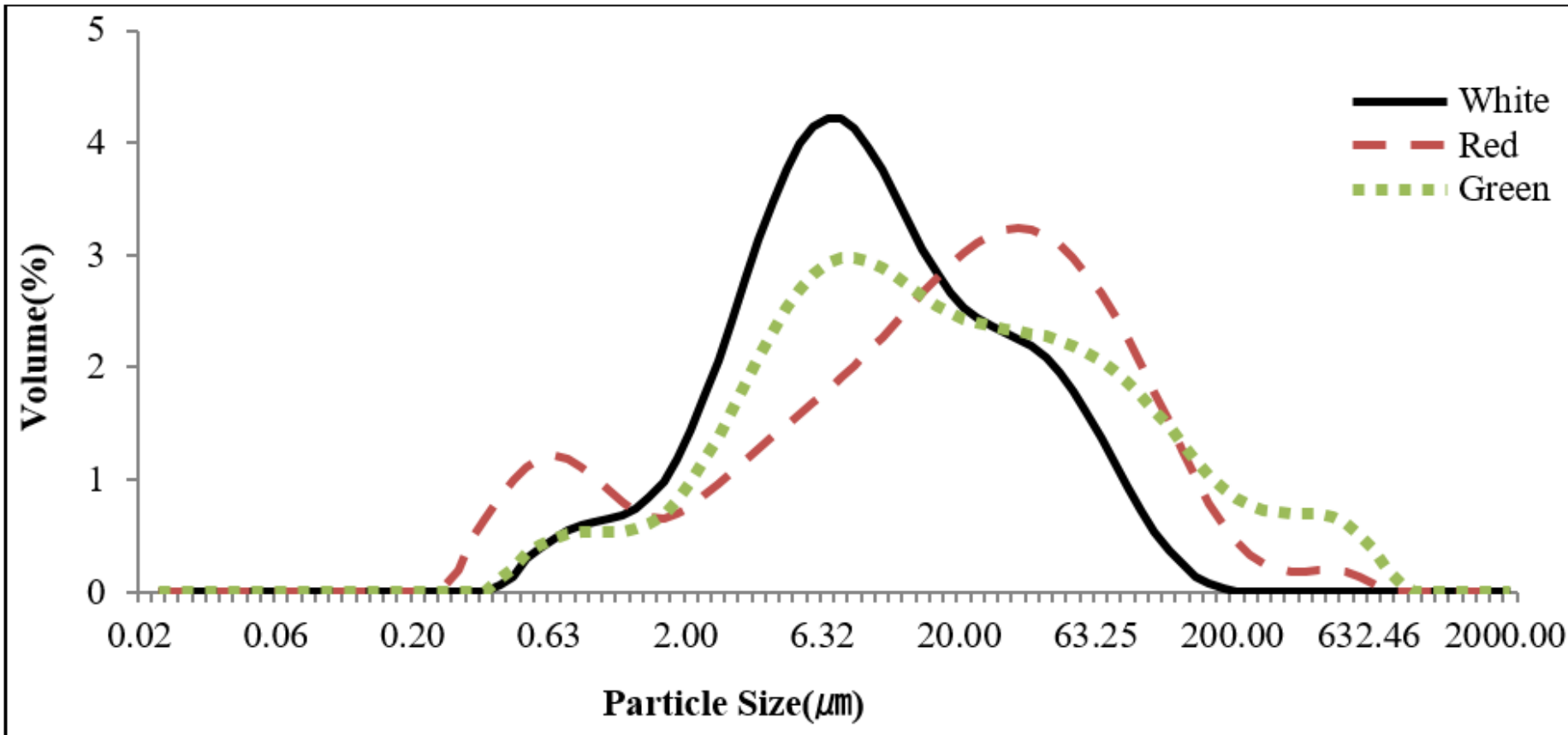

Figure 10

Particle size distribution of pigments 